\title{
Exploring Engineering Technology Students' Perception in Learning Statistics Using Minitab
}

\author{
Siti Mistima Maat \\ Department of Teaching and Learning Innovation, Faculty of Education, National University of Malaysia \\ E-mail: sitimistima@ukm.edu.my
}

\section{Doi:10.5901/mjss.2015.v6n3p823}

\begin{abstract}
The importance of learning statistics among engineers can be reflected to their real life applications. Using software as Minitab would ease the burden of analyzing data as well as making conclusion. This study aimed at exploring engineering technology students' perception in learning statistics using Minitab. Six students from a technical university were chosen to be the participants of the study. A semi structured interview was conducted in gathering the information on their perception in learning statistics using Minitab. A classroom observation was also being done in monitoring how well the students coped with the software. Most of the participants were being enthusiast in doing data analyzing work during class. However, some limitations of the software were revealed in terms of the disadvantages. The learning process has become interesting since dealing with real data lead to their experiential learning which makes them understand better.
\end{abstract}

Keywords: statistics; Minitab; perception; learning, statistics, engineering tecnology.

\section{Introduction}

The importance of statistics in engineering can be seen as the required subject in many engineering undergraduates' courses. Statistics has become a tool in solving most engineering problems that involve in making decision through data analyses using different techniques and statistical packages. Minitab is one of the statistical packages that is available in the market. The recent version has become more user friendly and provides more exciting features including its' graphical representations. This has made Minitab widely used in various fields of study such as engineering and business particularly in industry (Ramesh, 2009). Previous studies have shown that Minitab is used in measuring quality (Owlia \& Aspinwall, 1998) and comparing statistical software (Prvan, Reid, \& Petocz, 2002)

Technology has been widely used in statistics which has the greatest impact of education reform (Garfield, Hogg, Schau \& Whittinghill, 2002). The benefit of having technology in statistics education is to promote active learning as well as to encourage independent learning among students (Spinelli, 2001 \& Prvan et al., 2002). Minitab is statistical software that was developed 40 years ago with teaching statistics as the main purpose. It has become the leader in the quality improvement methodology. The user-friendly feature and well organized menus are matched with statistical reference books. The graphical features of Minitab plays important role in data exploration as well as visualization. The data interpretation can be done based on the results analysis. With the help of the Stats Guide command in Minitab, the interpretation makes the researcher understands the analysis better and they are able to make the justified conclusion. It covers from basic statistics to multivariate statistics as well as design of experiment.

The integration of statistical software in education helps the educators to reduce the difficulty in understanding complicated statistical formulae as well as to provide students with practical skills of operating the software that is commonly used in industry (Baglin \& Da Costa, 2012). This has become the justification of selecting the right statistical software that will be used in statistics education. Furthermore, with user friendly features, Minitab is one of the most applicable software to be used in engineering field. The requirement of understanding statistics among engineering students has become the main reason of choosing Mintab for this study particularly am

The chosen statistical software should meet the industrial need which focuses on producing work -ready graduates (Baglin \& Da Costa, 2012). Likewise, it is also familiar to advertisement with such skill like the ability to data processing using statistical software including Minitab, STATA, SPSS or SAS. Minitab has special features in helping students to understand statistical concept and develop statistical thinking (Ramesh, 2009). From basic descriptive statistics to inferential statistics, Minitab offers a wide range of data exploratory, estimations, regression and parametric and non parametric tests. Figure 1 shows some of the basic statistics menus that are commonly used in the analysis. The setting has similar feature as Excel with column type cells that can be used to key in data. 


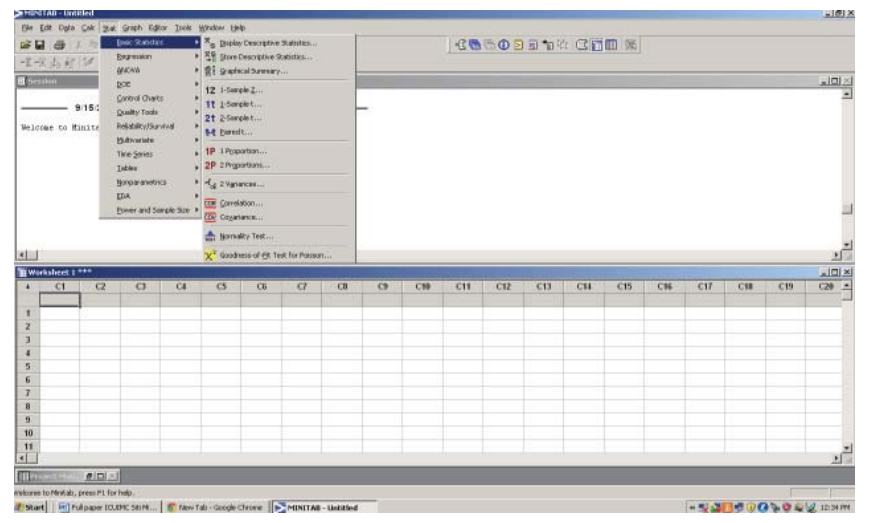

Figure 1. Minitab Version 14.0 with Basic Statistics Menus

Based on this scenario, using Minitab in teaching and learning statistics is recommended since introducing modern technology in classroom would enhance the students' understanding (Carney, 2004). This paper discusses on how the students' perceived on the use of Minitab in learning statistics covered from the obstacles, emotions, motivations that they faced during the learning process. The students' experience learning in statistics classroom has become easier with the help of Minitab that acts as tool in providing the fundamental conceptual on statistics. The role in facilitating the students' understanding begin with "doing activities using statistical software" to "understanding areas beyond statistics" (Petocz \& Reid, 2001). Furthermore, the statistical package depends on a specific field of study that is to be used in teaching and learning of statistics. It can be utilized as technological tool to establish additional knowledge in statistics.

Nevertheless, students are found to face problems in understanding basic statistics that include understanding some of the statistical terminology, using graphical representation and calculating the measures of central tendency and measures of dispersion. In addition to this, promoting statistical packages like Minitab would boost the students' interest in learning statistics and creating a new perspective in their statistical understanding. The interpretation of data analysis has been much easier with the help of some graphical representation that can be obtained easily from Minitab. Some questions that should be taken into consideration among the statistics educators include how to teach statistics effectively and how to determine that students are thinking statistically (Chance, 2002). The students should be encouraged to explore other statistical software with the intention to compare their satisfaction level towards the software. A study by Feinberg and Siekpe (2003) has compared students' satisfaction in using Minitab and SPSS. Satisfaction in their study is defined for self efficacy, engagement and disorientation has shown no significant difference between the Minitab and SPSS. However, their finding is consistent with the study which has been conducted by Adams (2004) in comparing Microsoft Excel and Minitab. The students are found to be indifferent in understanding statistics using both software.

The purpose of the study was to explore the students' perception in learning statistics using Minitab which is based on several aspects that cover the problems face by the students when using the statistical packages and how this statistical tool can help them in their learning. They were questioned on how Minitab can do in reducing their difficulties in learning statistics.

\section{Methodology}

\subsection{Research participants}

As the background of this study, all engineering technology students are compulsory to enroll in engineering statistics class in order to fulfill the requirement for their graduation. The two-credit subject covers topic like descriptive statistics, inferential statistics, hypotheses testing and linear regression. However, this study focused on analyzing data and presenting data using descriptive statistics only.

The analysis of data was done after three weeks of lesson. The first topic was descriptive statistics that was delivered using two types of approaches. The first approach was traditional teaching method which had required the lecturer explained on the basics statistics that covers mean mode, median, standard deviation and presenting data using graphical method such as box plot. As the second step, the lecturer introduced Minitab to the students in analyzing and producing the statistical output.

However, only six degree students from engineering technology specialization in welding quality of inspection 
program were chosen to be the participants of this study. The selection was based on the software that they used when doing their first statistics assignment and the first written quiz that was given after the first lesson. The quiz was taken from descriptive statistics questions. Two of them obtained low, moderate and high marks respectively. They were given two choices of software that they can use when completing their first assignment which was part of the students' assessment.

The class was taught by female lecturer who has 15 years teaching experience in mathematics and statistics. The lecturer has doctorate degree in mathematics education and master degree in pure mathematics. Based on the observation, she would start her class by explaining the lesson that has been conducted earlier and recapitulates her lesson of the day. In between the class session, she would let the students to perform data analysis using Minitab and she would explain on how to use Microsoft Excel in obtaining the same solution of the given problems. Beside the two teaching tools, she is used to explain the importance of doing calculation in statistics conventionally by using scientific calculator. To ease this small scale research, she has helped the researcher to set the questions for the quiz in order to select the participants of the study for the interview session.

An assignment based on analyzing three sets of data using descriptive statistics and graphical representation was also given to the students. The students were required to do interpretation on the output of the analysis. A semi structured interview was conducted to gather information from the selected students. In order to triangulate the content of the interview, a classroom observation was also done by the researcher to see the students' attitude towards using Minitab in their statistical subject.

\section{Results and Discussion}

The class was conducted in computer laboratory which took two hours to complete each session. As an introduction to Minitab, the lecturer explained some features of the software which are similar to Microsoft Excel. The students were taught on some short cut menus in order to have quick result of the analysis. They were seemed excited since they were no more complicated calculation like mathematics class. Some students were busy asking their classmates whenever they missed the lecturer's instruction. However, most of them were able to explore Minitab by themselves and this was the time the "undo" button was very useful to them. The lecturer was busy helping the students to troubleshoot some unexpected problems occurred during class. Those students who were late to class were busy asking their classmates what they have missed. The students, who were able to follow the lesson, looked more confident and excited to explore Minitab. Generally, the lecturer was able to control her class and the students looked happy learning new software when the class ended. Based on the observation, the lecturer was more focused on the Minitab rather learning statistics. This has become the one of the challenges when integrating statistical analysis tool in teaching statistics. Minitab acts as a teaching aid and should be incorporated wisely in the lesson. Otherwise, the learning outcome is not achievable since the prioritizing Minitab has become the lecturer's attention. However, the session has improved and manageable after several lessons. The lecturer was able to control her lesson as well as managing Minitab uncertain technical problems. The lecturer has to act to be technician in solving some technical problems that occur in her class.

Next, the interview session was conducted with the research participants. Four key themes emerged through semi structured interview with the students. By grouping the data accordingly, each theme was labeled as diffulty, advantages, recommendation and interest development. Triangulation of data was used by checking the students' weekly task and their participation during class.

\subsection{Students' difficulties in using Minitab}

Based on the interview, most of the students were excited to have class in computer lab since the previous mathematics classes were conducted in normal classrooms. However, the students were found to face the following problems;

- Since most students were first time using the statistical package then they were not familiar with the Minitab features although it is almost similar to Microsoft Excel.

- The lecturer expected the students to explore the extra features of Minitab while doing the analysis which resulted in producing the wrong output and the students were lost during learning process.

- The students had problem to enter the given data and choosing the right menu in order to answer the question posed by the lecturer.

As mentioned by one of the students;

"I would be very happy if the lecturer can spend more time on how to use Minitab. Although we know some commands and menus but the lecturer's guidance is more important". 
The student's comment was a remark to the lecture that spends more time on the software but less on the statistical concept. The eagerness of introducing new teaching tool in this context of study has made the learning outcome was partially achieved. Students were required a better exposure in using Minitab for their statistics lesson.

\subsection{The advantages of using Minitab in learning statistics}

The students have to learn the basic concept of statistics before using Minitab in solving tutorial or assignment. These students are satisfied with Minitab commands and menus which reduce their problem in manual calculation for some basic statistics. One student explained on what Minitab can do in helping her to understand statistics better.

"I am very happy that some of the questions in statistics can be solved easily using Minitab without going through complicated work using scientific calculator. The calculation of some basic descriptive statistics like mean and standard deviation can be done with one menu in Minitab".

Therefore, the requirement of more activities with Minitab is more beneficial in order to increase the familiarity with the software. A better learning perception would exist with linking the conceptual statistical knowledge and Minitab so that the idea of learning statistics is fun can be instilled among students. In addition to their learning experience, using Mintab can be an advantage to them which can be included in their curriculum vitae. It is a value added for them to be difference than other candidates when applying for a position.

\subsection{Students' recommendations on Minitab can be used in their study}

However, the students hoped that the lecturer would provide extra slot for them to learn Minitab as part of their learning material. Using Minitab in learning statistics would help them to gain more knowledge about the interpretation of the data that they analyzed. One student stated her recommendation on the how Minitab can be used in her final year project:

"Based on what I have learnt today, I can see that Minitab will be very useful in analyzing my data during my final year project. I will no longer rely on Microsoft Excel only to do the analysis as what my seniors used to do".

Another student stated the similar thoughts:

"I can use Minitab to produce more graphical presentations such as box plot and histogram in my final year report together with the interpretations of data analysis".

In addition, the assignments that these students produced were more than what the lecturer's expectation. They have come out with more meaningful interpretation on the given data analysis and able to explore Minitab more than what the lecturer has explained in class. Having the idea that Minitab plays an important role in learning statistics has made these students become more interested in the subject. This can be seen from their participation in class as well as the quality of their work.

Instead of applying Minitab in the students' final year project, another suggestion from these students is to have a special class on Minitab. Enhancement of statistical understanding can be integrated in learning Minitab. Final year students are advised to take Minitab before they go for industrial training so that the are well equipped with statistical analysis skill.

\subsection{Develop interet in statistics though the use of Minitab}

These students have gradually developed their interest in statistics although initially they were not attracted to learn the subject. Using Minitab, their learning process in understanding some difficult concept has become easier. Some complicated formula like calculating for standard deviation can be simplified using basic statistics menu in Minitab. Although the students can use scientific calculator to obtain the standard deviation value for the given set of data, using Minitab has saved their time from hassle of producing the answer. Figure 2 shows sample standard deviation formulae, while figure 3 shows the standard deviation command in Minitab for a set of data. When the students are exposed to comparison of different methods in learning statistics, gradually their interest in statistics will be developed. They learn statisics at their pace while exploring what Minitab can do for them.

$$
s=\sqrt{\frac{1}{n-1} \sum_{i=1}^{n}\left(X_{i}-\bar{X}\right)^{2}}
$$

Figure 2. Sample standard deviation formulae 


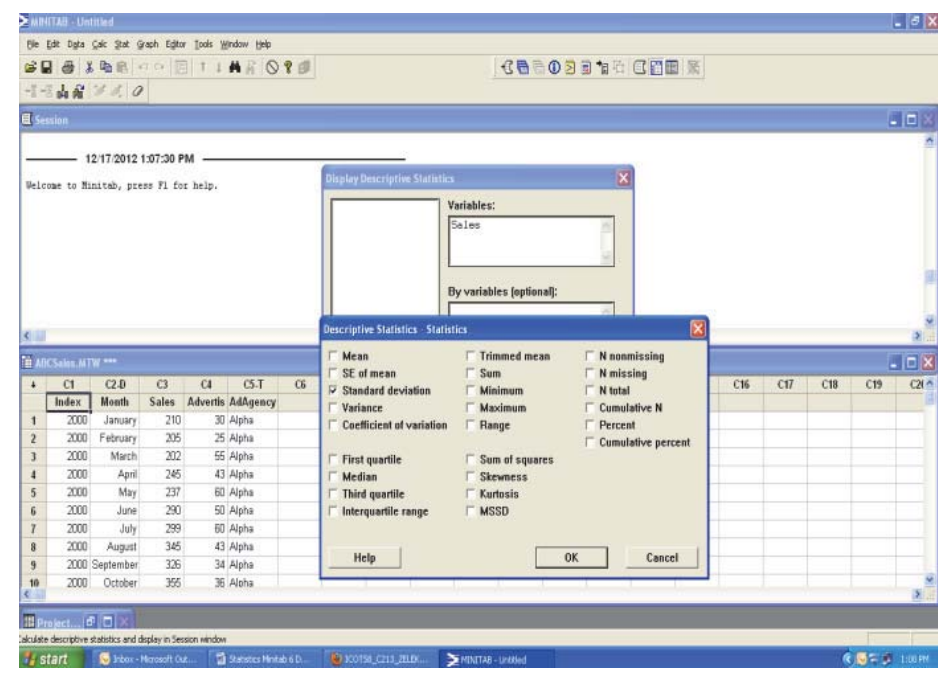

Figure 3. Standard deviation command in Minitab version 14.0

\section{Conclusion}

What the students have perceived in this study is Minitab provides an alternative in making the analysis more readable and opportunity to learn new statistical tool in statistics. This leads to a better understanding in their statistics lesson because the class is conducted in computer laboratory and not in normal classroom. In order to enhance engineering technology students' understanding in learning statistics, some recommendations are proposed as follows (Aliaga et al., 2010);

Using commonly used statistical packages like Minitab would help the students to apply in their final year project especially that involves with data analyses.

Students should develop the statistical fundamental as well as statistical thinking. This can be obtained through the enhancement on conceptual statistical understanding rather than procedural understanding.

The lecturers should use a case study with real data in order to promote active learning among their students. Teamwork and collaboration project would help the students to construct statistical knowledge

To incorporate the teaching and learning of statistics and the used of Minitab would change the students' perception on statistical engineering. Their statistical understanding would be improved as they may see the importance of statistics in their field of study. Therefore, to foster students' interest in statistics, then using statistical package like Minitab would enhance their understanding in statistics. Students would also face more challenges if they are given real data especially through case studies. Exploring all the menus and comprehend statistical knowledge will be more meaningful among these students. However, the educators have to bear in mind that the students' competence in operating the statistical software will not increase their understanding of the statistical concept (Baglin \& Da Costa, 2012). How they able to complete the analyses without instructions and how they use shortcuts in dealing with problems are the evident of the students' competency in using the statistical software. The ability to explore, analyze and produce statistical output should be the main focus when introducing any statistical software to students. This shows a strong linking between statistical knowledge and understanding on how Minitab works would lead to a positive learning experience among students.

The emergence of statistical analysis tools are needed in fulfilling the needs in various field including industry. By giving the opportunity to students in learning the statistical software will give them advantage as value added in their curriculum vitae. Skill in operating Minitab and understanding statistical output will give them benefit in getting them ready in industry. Therefore, another consideration should be given to the type of statistical software that is commonly used in industry. This would lead to the decision of selecting the most suitable software for the learning purposes (Baglin \& $\mathrm{Da}$ Costa, 2012). The accessibility of the software should be reachable between students in the institution and their industry linkages. 


\section{References}

Adams, C.N.(2004). Students' Perception of Learning Statistics: Comparing Excel and Minitab. Proceedings of Academy Information and Management Science. Volume 8, Number 1, New Orleans.

Aliaga, M., Cobb, G., Cuff, C., Garfield, J., Gould, R., Lock, R., Moore, T., Guidelines for Assessment and Instruction in Statistics Education, 2010. Available at: www.amstat.org/education/gaise/GaiseCollege_Full.pdf(Retrieved on 28 May 2012).

Baglin, J., \& Costa, C.D. (2012). A theoretical framework for developing statistical package competence as an outcome of statistical literacy. http://icots.net/roundtable/docs/Wednesday/IASE2012_Baglin_DaCosta.pdf (Retrieved on 17 Dec 2012).

Chance, B.L. (2002). Components of Statistical Thinking and Implications for Instruction and Assessment. Journal of Statistics Education, Volume 3, Number 10. Retrieved on 17 December 2012 at www.amstat.org/publications/jse/v10n3/chance.html

Davis, G. Teaching with Minitab and SPSS in a Business School Environment. Maths \& Stats, August, pp.1-6.

Feinber, M. \& Siekpe, J. (2003). An Empirical Comparison of Student User Satisfaction Between SPSS and Minitab. College Student Journal, 37(4); 509-514.

Garfield, J., Hogg, B., Schau, C., \& Whittinghill, D. (2002). First courses in statistical science: The status of educational reform efforts. Journal of Statistics Education, 10 at http://www.amstat.org/publications/jse/v10n2/garfield.html. (Retrieved on 11 Dec3mb34 2012)

McCarney, J. Effective use of staff development in ICT. European Journal of Education, 2004, 27, (1), 61 - 72.

N. Ramesh, The Role of Minitab in teaching and learning statistics.vol 9, no 3, August, MSOR Connections-October,2009, pp. 9-13.

N. William Statistical Engineering, a Missing Ingredient in the Introductory Statistics Course, Quality Engineering, pp.193-200.

Owlia, M., \& Aspinwall, E. (1998). A framework for measuring quality in engineering education. Total Quality Management \& Business Excellence, 9, 501-518.

Petocz, P., \& Reid, A. (2001). Students' experience of learning in statistics. Quaestiones Mathematicae, Supplement 1, 37-45.

Prvan, T., Reid, A., \& Petocz, P. (2002). Statistical laboratories using Minitab, SPSS and Excel: A practical comparison. Teaching Statistics, 24(2), 68-75.

Spinelli, M.A.(2001). The use of technology in teaching business statistics. Journal of Education for Business, 77(1)_, 41-45. 